\title{
Diclofenac- and Pantoprazole-Induced Rhabdomyolysis: A Potential Drug Interaction
}

\author{
Yusuf Haydar Ertekin ${ }^{1}$ Burkay Yakar $^{2} \cdot$ Hülya Ertekin ${ }^{3} \cdot$ Ayşegül Uludağ ${ }^{1} \cdot$ Murat Tekin $^{1}$
}

Published online: 22 July 2015

(c) The Author(s) 2015. This article is published with open access at Springerlink.com

\begin{abstract}
Background Drugs represent one of the etiologic causes of acute rhabdomyolysis (AR) with drug-induced rhabdomyolysis most commonly associated with HMG-CoA reductase inhibitors. AR etiology can also result from the use of diclofenac, a non-steroidal anti-inflammatory drug, and omeprazole, a proton pump inhibitor. Cases of AR triggered by pantoprazole have never before been reported, although it has been observed that its inclusion in multiple drug therapies can result in muscle events.

Case presentation A 45-year-old man presenting with complaints of fatigue and extensive body pain was diagnosed with acute rhabdomyolysis. His symptoms started on the fourth day of the concomitant use of diclofenac and pantoprazole. The patient was using diclofenac 50-mg tablets once daily for 1 month and pantoprazole 40-mg tablets once daily during the previous week for headaches and pyrosis, resulting in an increase in his creatinine kinase levels to $3114 \mathrm{IU} / \mathrm{L}$ (reference range 24-190 IU/L) on the fifth day of concomitant use. His creatinine kinase levels returned to normal and his complaints disappeared after the seventh day of discontinuation of both treatments.

Discussion A third case of diclofenac-induced rhabdomyolysis was defined in which, different from previous cases, AR was detected during the concomitant use of diclofenac and pantoprazole. The timing of the symptom
\end{abstract}

Yusuf Haydar Ertekin

dr.ertekin@comu.edu.tr

1 Department of Family Medicine, Canakkale Onsekiz Mart University, Canakkale, Turkey

2 Corum Gulabibey Family Health Center, Corum, Turkey

3 Department of Psychiatry, Canakkale Onsekiz Mart University, Canakkale, Turkey development and the limited number of AR cases induced by diclofenac and pantoprazole suggested a drug interaction.

Conclusion The close relationship between diclofenac and pantoprazole, and the cytochrome $\mathrm{P} 450$ and P-glycoprotein systems offers a strong indication that a drug interaction may be occurring. While evaluating the side effects of drugs in patients undergoing monotherapy, clinicians should also consider the mechanisms that play a part in drug absorption and distribution.

\section{Key Points}

While drugs can cause acute rhabdomyolysis individually, they can also interact with other drugs by cytochrome $\mathrm{P} 450$ and P-glycoprotein mechanisms to bring on the syndrome.

Clinicians should evaluate drug interactions in patients taking two or more medications.

\section{Introduction}

Acute rhabdomyolysis (AR) is a clinical syndrome that occurs when the electrolytes and myoglobin that are released upon skeletal muscle damage enter into the circulation system. There are several ways in which AR may occur [1], one of which is drugs (Fig. 1).

A comprehensive study was carried out in 2011 using 2004-2009 data of the US Food and Drug Administration (FDA) to reveal which drugs may be associated with rhabdomyloysis. The etiologies of 16,435 drug-induced 


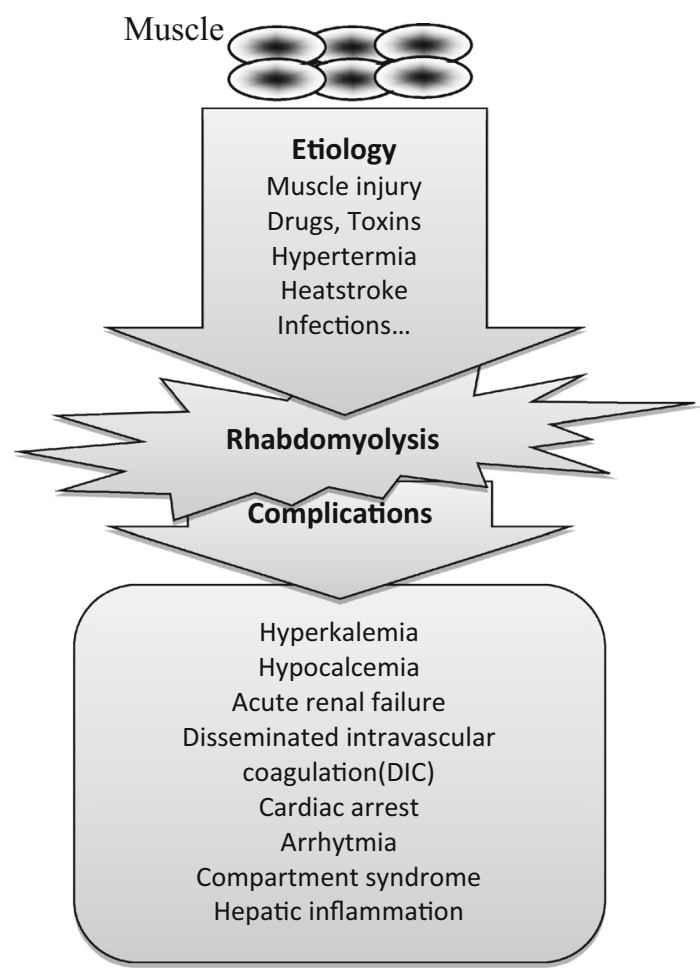

Fig. 1 Etiology of acute rhabdomyolysis and its complications

cases of rhabdomyloysis involved HMG-CoA reductase inhibitors or statins ( $n=4325,26.3 \%)$ as the first suspect. A total of 100 cases were reported for diclofenac and 99 for omeprazole, a proton pump inhibitor, while there were no reports of cases associated with pantoprazole. The cases of drug-induced rhabdomyolysis in previous literature were also associated with statins, and the frequency is similar to that reported in the abovementioned report. That said, drug interactions could not be assessed because the FDA data did not include that level of systematic information [2].

The gastric side effects of non-steroidal anti-inflammatory drugs (NSAIDs) are well known, and their concomitant or subsequent combination with proton pump inhibitors is common. A review of adverse drug reactions, creatinine kinase elevations, and muscle events, including muscle weakness, myopathy, myositis, and polymyositis, analyzed such multiple drug regimens and found that the addition of pantoprazole to a treatment regimen was the cause of all muscle events, aside from myalgia [3].

\section{Case Presentation}

A 45-year-old man was referred to hospital complaining of fatigue and extensive body pain. His medical history included stress-induced headaches that had been present for almost the entire previous year, for which he began using diclofenac at $50 \mathrm{mg} /$ day as the frequency of headaches had increased during the prior month. He was referred to a physician for pyrosis, 1 week prior to presenting at the hospital, and was prescribed pantoprazole at $40 \mathrm{mg} / \mathrm{day}$. He continued using diclofenac for the ongoing headaches. He started to experience pain in his leg muscles on the fourth day of the diclofenac and pantoprazole combination regimen and used two 50-mg doses of diclofenac to control the pain. The muscle pain became more widespread on the fifth day, and the patient also developed fatigue.

An examination revealed a blood pressure of $120 / 80 \mathrm{mmHg}$ and a pulse of $76 \mathrm{bpm}$, full and rhythmic. Cardiac sounds were normal and the patient had no specific chest pain. Muscular strength was good; however, the patient complained of muscle tenderness upon palpation. Neurological and general system examinations were normal; no abnormal findings were seen in an electrocardiogram; and an abdomen ultrasound revealed no pathology, aside from an abdominal gas distention. A laboratory analysis revealed high levels of muscle destruction products, the foremost of which was creatinine kinase (Table 1). Glucose, urea, creatinine, cholesterol levels, amylase, direct and indirect bilirubin, electrolytes, antistreptolysin O, C-reactive protein, rheumatoid factor, and thyroid hormones were all within their normal ranges.
Table 1 Laboratory parameters of patient

\begin{tabular}{lllc}
\hline & Admission & 7 days after & Reference range \\
\hline Glucose (mg/dL) & 96 & N/A & $70-105$ \\
ALP (alkaline phosphatase) (IU/L) & 56 & 51 & $64-306$ \\
SGPT (IU/L) & 45 & 12 & $0-42$ \\
SGOT (IU/L) & 88 & 14 & $5-34$ \\
CK (IU/L) & 3114 & 67 & $24-190$ \\
Creatinine (mg/dL) & 0.76 & 0.67 & $0.75-1.25$ \\
CRP (mg/dL) & 0.88 & 0.59 & $0-5$ \\
LDH (IU/L) & 230 & 168 & $125-220$
\end{tabular}

$A L P$ alkaline phosphatase, $C K$ creatine kinase, $C R P$ C-reactive protein, $L D H$ lactate dehydrogenase, $n / a$ not available, $S G O T$ serum glutamic oxaloacetic transaminase, $S G P T$ serum glutamic pyruvic transaminase 
A cardiac pathology was excluded because the electrocardiographic assessments and cardiac sounds were normal, and because the patient did not describe any pain that would indicate an infarct, and test results and findings were stable on the following days. Liver and biliary tract pathologies were excluded by ultrasound. AR was considered as a pre-diagnosis, as there was a chronologic alignment between the patient's clinical representation and the medications he used, and this was supported by the laboratory parameters. Both medications were discontinued and the patient was followed up for 1 week, during which no medical interventions were carried out, aside from a recommendation of general hydration. The AR diagnosis was confirmed because his complaints disappeared, with his laboratory values returning to the normal range, a stable electrocardiogram, and other systemic examinations being found within normal ranges.

\section{Discussion}

To date, among the cases involving NSAIDs, two cases were reported that include diclofenac-induced rhabdomyloysis $[4,5]$. The patient detailed in this study was referred with extensive pain and fatigue, and represents the third case in which rhabdomyloysis developed while using 100-mg/day diclofenac tablets. The other two cases were induced by diclofenac alone, with no interaction with other drugs. Of these, one patient was admitted with pain that increased after the patient took $200 \mathrm{mg}$ of diclofenac within 2 days (50 mg tablet/twice a day) for joint pain [4]. The other case involved a patient who used diclofenac to ease an acute exacerbation of gout. The patient was referred to a physician on the 13th day of intramuscularly self-administered diclofenac at $75 \mathrm{mg}$ per day for 6 days, followed by $75 \mathrm{mg}$ orally three times a day for 7 days. Unlike the previous case, this patient was referred to the hospital because of erythematous pruritic eruptions that developed on various parts of his body [5].

\section{Interaction Potential of Cytochrome P450 and Pantoprazole}

While drugs can cause AR individually, they can also interact with other drugs to bring on the syndrome. Diclofenac is an NSAID that is well documented in cases of drug interactions [6]. Cytochrome P450 (CYP) enzymes play a crucial role in these interactions. The $C Y P 1, C Y P 2$, and $C Y P 3$ gene families are overall responsible for drug metabolism, and the similarities between the amino acid sequences within a gene family are at least $40 \%$, although the level of similarity may increase to $85 \%$ between subgroups. The genetic polymorphisms in these genes alter the biotransformation of the drug. While fast metabolizers have increased enzyme activity, slow metabolizers show decreased enzyme activity. Among these genes, the CYP3A4 gene displays no polymorphism, as erythromycin strongly inhibits this pathway. Theophylline, which is metabolized through this pathway, when used with erythromycin, returns to the CYP1A2 pathway and cannot reach toxic concentrations [7-9]. That said, to date, no such theory has been put forward for diclofenac and pantoprazole in the CYP enzyme system. Diclofenac is metabolized through CYP2C9, and pantoprazole is metabolized through CYP2C19. The fact that they are metabolized through the same subgroup (2C) can be associated with a possible drug interaction. This possibility of interaction between diclofenac and pantoprazole has been investigated in a randomized crossover trial of 24 subjects, and the results showed that the peak plasma concentrations of diclofenac are sustained in a stable range, and that diclofenac does not affect the pharmacokinetics of pantoprazole, meaning that this combination is completely safe [10]. However, the results of an in-vitro study using diclofenac as a substrate marker for human liver microsomes suggested the contrary. According to this study, proton pump inhibitors, the strongest one being pantoprazole, carry a strong potential for drug interaction by inhibiting the activity of CYP enzymes, and it was underlined that drug interactions are significantly more pronounced in weak metabolizers with an enzyme deficiency [11].

\section{P-glycoprotein and Drug Interactions}

P-glycoprotein (P-gp) is an adenosine triphosphate-dependent efflux transprotein that is found in the membranes of the enterocytes. It is expressed by the MDRI gene in humans and can be found in various organs, including the liver, kidneys, intestinal region, and blood-brain barrier. P-gp actively pumps its substrates xenobiotics to the extracellular space and decreases their intracellular concentrations [12]. Proton pump inhibitors, including pantoprazole, anti-arrythmic drugs, anticancer drugs, antibiotics, and antidepressant drugs, inhibit P-gp, and therefore the modulation of this pump plays a crucial role in drug-drug interactions $[12,13]$.

\section{Conclusion}

The FDA recommends that clinicians check CYP-mediated potential drug interactions routinely [14]. In this case report, a case of diclofenac- and pantoprazole-induced AR is evaluated for drug-interaction mechanisms, and different perspectives are presented. While evaluating the patients with side effects of drugs, the CYP and P-gp mechanisms 
that play roles in drug absorption and distribution should be considered.

Acknowledgments No sources of funding were used to assist in the preparation of this case report. Yusuf Haydar Ertekin, Burkay Yakar, Hülya Ertekin, Ayşegül Uludağ, and Murat Tekin declare that they have no conflicts of interest that are directly relevant to the content of this case report.

\section{Compliance with ethical standards}

Informed consent Written informed consent of the participant was obtained after the nature of the procedures had been fully explained.

Ethics and dissemination The case report was carried out in agreement with the latest version of the Declaration of Helsinki.

Open Access This article is distributed under the terms of the Creative Commons Attribution-NonCommercial 4.0 International License (http://creativecommons.org/licenses/by-nc/4.0/), which permits any noncommercial use, distribution, and reproduction in any medium, provided you give appropriate credit to the original author(s) and the source, provide a link to the Creative Commons license, and indicate if changes were made.

\section{References}

1. Khan FY. Rhabdomyolysis: a review of the literature. Neth J Med. 2009;67:272-83.

2. Oshima Y. Characteristics of drug-associated rhabdomyolysis: analysis of 8610 cases reported to the U.S. Food and Drug Administration. Intern Med. 2011;50:845-53.
3. Clark DWJ, Strandell J. Myopathy including polymyositis: a likely class adverse effect of proton pump inhibitors? Eur J Clin Pharmacol. 2006;62:473-9.

4. Delrio FG, Park Y, Herzlich B, Grob D. Case report: diclofenacinduced rhabdomyolysis. Am J Med Sci. 1996;312:95-7.

5. Knobloch K, et al. Rhabdomyolysis after administration of diclofenac. Unfallchirurg. 2005;108:415-7.

6. Guis S, Mattei J-P, Cozzone PJ, Bendahan D. Pathophysiology and clinical presentations of rhabdomyolysis. Jt Bone Spine. 2005;72:382-91.

7. Yükse N. Cytochrome P450 enzyme system and drug interactions. [Sitokrom P450 Enzim Sistemi ve İlaç Etkileşmeleri]. Klin. Psikiyatr. 2001;5-16. Available from: http://www.klinikpsikiyatri. org/files/journals/1/305.pdf. Accessed 16 Aug 2014.

8. Anzenbacher P, Anzenbacherová E. Cytochromes P450 and metabolism of xenobiotics. Cell Mol Life Sci. 2001;58:737-47.

9. Üney K, Traş B. Use of in vivo probe drugs in the determination of activities of drug metabolizing enzymes. Genel Tip Derg. 2006;16(4):203-11.

10. Bliesath H, Huber R, Steinijans VW, et al. Lack of pharmacokinetic interaction between pantoprazole and diclofenac. Int $\mathrm{J}$ Clin Pharmacol Ther. 1996;34:152-6.

11. Li X-Q, Andersson TB, Ahlström M, Weidolf L. Comparison of inhibitory effects of the proton pump-inhibiting drugs omeprazole, esomeprazole, lansoprazole, pantoprazole, and rabeprazole on human cytochrome P450 activities. Drug Metab Dispos. 2004;32:821-7.

12. Balayssac D, Authier N, Cayre A, Coudore F. Does inhibition of P-glycoprotein lead to drug-drug interactions? Toxicol Lett. 2005;156:319-29.

13. Pauli-Magnus C, Rekersbrink S, Klotz U, Fromm MF. Interaction of omeprazole, lansoprazole and pantoprazole with P-glycoprotein. Naunyn Schmiedebergs Arch Pharmacol. 2014;364:551-7.

14. Zhang L, Zhang YD, Zhao P, Huang S-M. Predicting drug-drug interactions: an FDA perspective. AAPS J. 2009;11:300-6. 